\title{
A phase II study of five peptides combination with oxaliplatin-based chemotherapy as a first-line therapy for advanced colorectal cancer (FXV study)
}

Shoichi Hazama ${ }^{* *}$, Yusuke Nakamura ${ }^{2}$, Hiroaki Tanaka ${ }^{3}$, Kosei Hirakawa $^{3}$, Ko Tahara $^{4}$, Ryoichi Shimizu ${ }^{5}$, Hiroaki Ozasa ${ }^{5}$, Ryuichi Etoh ${ }^{5}$, Fumiaki Sugiura ${ }^{6}$, Kiyotaka Okuno ${ }^{6}$, Takumi Furuya ${ }^{7}$, Taku Nishimura $^{8}$, Koichiro Sakata ${ }^{8}$, Kazuhiko Yoshimatsu ${ }^{9}$, Hiroko Takenouchi ${ }^{1}$, Ryouichi Tsunedomi ${ }^{1}$, Yuka Inoue ${ }^{1}$, Shinsuke Kanekiyo ${ }^{1}$, Yoshitaro Shindo ${ }^{1}$, Nobuaki Suzuki ${ }^{1}$, Shigefumi Yoshino ${ }^{1}$, Hirokazu Shinozaki ${ }^{10}$, Akira Kamiya ${ }^{10}$, Hiroyuki Furukawa ${ }^{10}$, Takeharu Yamanaka ${ }^{11}$, Tomonobu Fujita ${ }^{12}$, Yutaka Kawakami ${ }^{12}$ and Masaaki Oka

\begin{abstract}
Background: We previously conducted a phase I trial for advanced colorectal cancer (CRC) using five HLA-A*2402-restricted peptides, three derived from oncoantigens and two from vascular endothelial growth factor (VEGF) receptors, and confirmed safety and immunological responses. To evaluate clinical benefits of cancer vaccination treatment, we conducted a phase II trial using the same peptides in combination with oxaliplatin-based chemotherapy as a first-line therapy.
\end{abstract}

Methods: The primary objective of the study was the response rates (RR). Progression free survival (PFS), overall survival (OS), and immunological parameters were evaluated as secondary objective. The planned sample size was more than 40 patients for both HLA2402-matched and -unmatched groups. All patients received a cocktail of five peptides ( $3 \mathrm{mg}$ each) mixed with $1.5 \mathrm{ml}$ of IFA which was subcutaneously administered weekly for the first 12 weeks followed by biweekly administration. Presence or absence of the HLA-A*2402 genotype were used for classification of patients into two groups.

Results: Between February 2009 and November 2012, ninety-six chemotherapy naïe CRC patients were enrolled under the masking of their HLA-A status. Ninety-three patients received mFOLFOX6 and three received XELOX. Bevacizumab was added in five patients. RR was $62.0 \%$ and $60.9 \%$ in the HLA-A*2402-matched and -unmatched groups, respectively $(p=0.910)$. The median OS was 20.7 months in the HLA-A*2402-matched group and 24.0 months in the unmatched group (log-rank, $p=0.489$ ). In subgroup with a neutrophil/lymphocyte ratio (NLR) of < 3.0, patients in the HLA-matched group did not survive significantly longer than those in the unmatched group (log-rank, $p=0.289$ ) but showed a delayed response.

Conclusions: Although no significance was observed for planned statistical efficacy endpoints, a delayed response was observed in subgroup with a NLR of < 3.0. Biomarkers such as NLR might be useful for selecting patients with a better treatment outcome by the vaccination.

Trial registration: Trial registration: UMIN000001791.

Keywords: Peptide vaccine, Peptide cocktail, Colorectal cancer, Phase II study, FOLFOX, Chemotherapy

\footnotetext{
*Correspondence: hazama@yamaguchi-u.ac.jp

'Department of Digestive Surgery and Surgical Oncology, Yamaguchi

University Graduate School of Medicine, Ube, Japan

Full list of author information is available at the end of the article
} 


\section{Background}

Colorectal cancer (CRC) is the third most common cancer and the second leading cause of cancer-related death in industrialized countries [1]. In the past decade, a combination treatment of fluorinated-pyrimidine with irinotecan (FOLFIRI) or oxaliplatin (FOLFOX, XELOX), with or without monoclonal antibodies such as anti-vascular endothelial growth factor (VEGF) antibody or anti-epidermal growth factor receptor (EGFR) antibody, has markedly improved the prognosis of patients with metastatic CRC (mCRC) [2-6]. However, most of the patients reveal progression of the disease due to chemo-resistance and lose their lives.

As an attempt to validate a new treatment modality to overcome the limited disease control status of mCRC, we conducted a combination treatment of five therapeutic epitope-peptides with chemotherapy. Recent developments in genome-based technologies have enabled us to obtain comprehensive gene expression profiles of malignant cells and compare them with normal cells [7]. We had previously identified three oncoantigens, RNF43 (ring finger protein 43) [8], 34 $\mathrm{kDa}$ translocase of the outer mitochondrial membrane (TOMM34) [9], and KOC1 (IMP-3; IGF-II mRNA binding protein 3) [10], as targets for the development of cancer peptide vaccines for CRC.

Although immunotherapy using tumor infiltrating cells (TIL) or vaccine treatment are promising modalities for the treatment of cancer, recent reports have indicated several mechanisms in tumor tissues which make cancer cells escape from immune system attacks [11]. For example, the limited antitumor effects of cytotoxic $\mathrm{T}$ lymphocytes (CTL) were explained by tumor heterogeneity; a subset of tumor cells revealed the down-regulation or absence of human leukocyte antigen (HLA) or targeted antigen proteins [12,13]. Since the growth of solid neoplasms is almost always accompanied with neovascularization [14], which is associated with the expression of vascular endothelial growth factor receptor 1 (VEGFR1) [15] and/or VEGFR2 [16], our vaccine treatment also included the peptides derived from VEGFR1 and VEGFR2 that target neovascular endothelial cells. We selected five HLA-A*2402restricted peptides derived from RNF43, TOMM34, KOC1, VEGFR1, and VEGFR2 for the clinical trial due to the abundance of the HLA-A*2402 allele in the Japanese population (an allelic frequency of approximately 60\%) [17]. We previously performed a phase I study of a combination vaccine treatment for $\mathrm{mCRC}$, and confirmed the safety and the promising potential of our five-peptidecocktail treatment to improve the prognosis of advanced CRC [18].

FOLFOX (or XELOX) with/without bevacizumab is a widely-used chemotherapy [4] and has been reported to possibly reduce the number of Tregs [19]. We therefore conducted a phase II study of a cancer vaccine consisting of five peptides in combination with oxaliplatin-based chemotherapy as a first-line therapy for advanced CRC.

The purpose of this study was to evaluate the clinical benefit of this cancer vaccine treatment by adding to oxaliplatin-based chemotherapy. Furthermore, we explored a predictive biomarker for its response and for the selection of patients who are likely to exhibit better treatment outcomes following the vaccine treatment. We here demonstrate a promising result of our combination immuno-chemotherapy and predictive biomarkers for immunotherapy.

\section{Patients and methods}

\section{Patients and eligibility criteria}

Patients were eligible for enrollment when they were $\geq$ 20 years old with a histologically confirmed advanced CRC, had one or more measurable lesions according to the Response Evaluation Criteria in Solid Tumors version 1.0 (RECIST), were naïve for chemotherapy, had adequate functions of critical organs, had an ECOG performance status (PS) of 0 or 1 , and had a life expectancy of $\geq 3$ months. The exclusion criteria were $\mathrm{CNS}$ involvement, second primary tumors, active infectious disease, any steroid treatment, or any prior peptide vaccination therapies. Written informed consent was obtained from each patient at the time of enrollment. The study was carried out in accordance with the Helsinki declaration on experimentation on human subjects, was approved by the Institutional Ethics Review Boards of Yamaguchi University (H20-102) and each study site, and was registered in the UMIN Clinical Trials Registry as UMIN000001791.

\section{Peptides}

The RNF43-721 (NSQPVWLCL) [20], TOMM34-299 (KLRQEVKQNL) [9], KOC1(IMP-3)-508 (KTVNELQNL) [21], VEGFR1-1084 (SYGVLLWEI) [22] and VEGFR2-169 (RFVPDGNRI) [23] peptides restricted with HLA-A*2402 were synthesized by American Peptide Company Inc. (Sunnyvale, CA, USA) according to a standard solid-phase synthesis method, and were purified by reverse-phase high performance liquid chromatography (HPLC). The purity (>95\%) and the identity of the peptides were determined by analytical HPLC and mass spectrometry analysis, respectively. Endotoxin levels and the bio-burden of these peptides were tested and determined to be within acceptable levels as Good Manufacturing Practice grade for vaccines.

\section{Study design}

This phase II, single arm, non-randomized, HLA-A status double-blind study was conducted to assess the efficacy of this combination therapy for first-line treatment for advanced CRC. The therapy consisted of a cocktail of five 
therapeutic epitope-peptides in addition to oxaliplatincontaining chemotherapy. Although the peptides used in this study were HLA-A*2402 restricted peptides, all enrolled patients whose HLA-A status were double-blinded were administrated the same regime of peptide cocktail and oxaliplatin-containing chemotherapy.

The cocktail of $3 \mathrm{mg}$ each of five peptides derived from RNF43-721, TOMM34-299, KOC1-508, VEGFR1-1084 and VEGFR2-169, was mixed with $1.5 \mathrm{ml}$ of incomplete Freund's adjuvant (IFA) (Montanide ISA51; Seppic, Paris, France) and administered subcutaneously into the thigh or axilla regions on day 1 of each week for 13 weeks, then the vaccination schedule was reduced to once every 2 weeks. Vaccination was continued even if the disease progressed when the patient wished and a primary doctor who provided additional chemotherapies agreed.

Oxaliplatin-containing regimens were administrated concurrently with the vaccination. Detailed informations of the chemotherapies were described in Additional file 1. Briefly, mFOLFOX6 [24,25] consisted of oxaliplatin $\left(85 \mathrm{mg} / \mathrm{m}^{2}\right)$ with leucovorin $\left(400 \mathrm{mg} / \mathrm{m}^{2}\right)$, followed by a FU $\left(400 \mathrm{mg} / \mathrm{m}^{2}\right)$ bolus, and then $2,400 \mathrm{mg} / \mathrm{m}^{2}$ continuous infusion with/without bevacizumab (5 mg/kg) [4]. This treatment was repeated every 14 days. XELOX [4] consisted of oxaliplatin $\left(130 \mathrm{mg} / \mathrm{m}^{2}\right)$ on day 1 followed by oral capecitabine $\left(1,000 \mathrm{mg} / \mathrm{m}^{2}\right)$ twice daily on days 1 through 14 of a 21 -day cycle with/without bevacizumab at a dose of $7.5 \mathrm{mg} / \mathrm{kg}$.

\section{Study objectives}

The primary objective was the comparison of the efficacy of the peptide-cocktail plus oxaliplatin-containing regimen on patients with HLA-A*2402 compared with those without HLA-A*2402 by assessing the objective response rate (ORR; complete response (CR) and partial response (PR)).
Secondary objectives included comparisons between the two groups for progression free survival (PFS), overall survival (OS), safety, and tolerability. Exploratory end points included the assessments of tumor and blood-based immunological biomarkers.

\section{Assessments}

Medical history, physical examination, chest X-ray, ECG, and carcinoembryonic antigen (CEA) measurements were performed within 21 days before starting the treatment. Assessments of vital signs, ECOG performance status, height, weight, and routine blood analysis (hematology and chemistry) were performed within 7 days of starting the treatment. During treatment, physical examination, hematology, and biochemistry analyses were repeated on day 1 of every treatment cycle. Tumor assessments (computed tomography scan, magnetic resonance imaging) were made before starting the study treatment and were repeated every 4 to 8 weeks after the treatment. The RECIST guidelines were used to define all responses. Signs of hematological toxicity and non-hematological toxicity were assessed according to CTCAE during therapy and for 28 days after the last study drug dose.

\section{Immunological biomarkers}

We investigated the neutrophil/lymphocyte ratio (NLR) and the peripheral blood lymphocyte counts per the entire white blood cells (lymphocyte-\%) before the treatment as predictive markers of the efficacy of the vaccination. NLR and lymphocyte-\% were determined immediately at each study site.

\section{Statistical analysis}

This study was designed to test the hypothesis that a regime consisting of vaccination plus oxaliplatin-containing

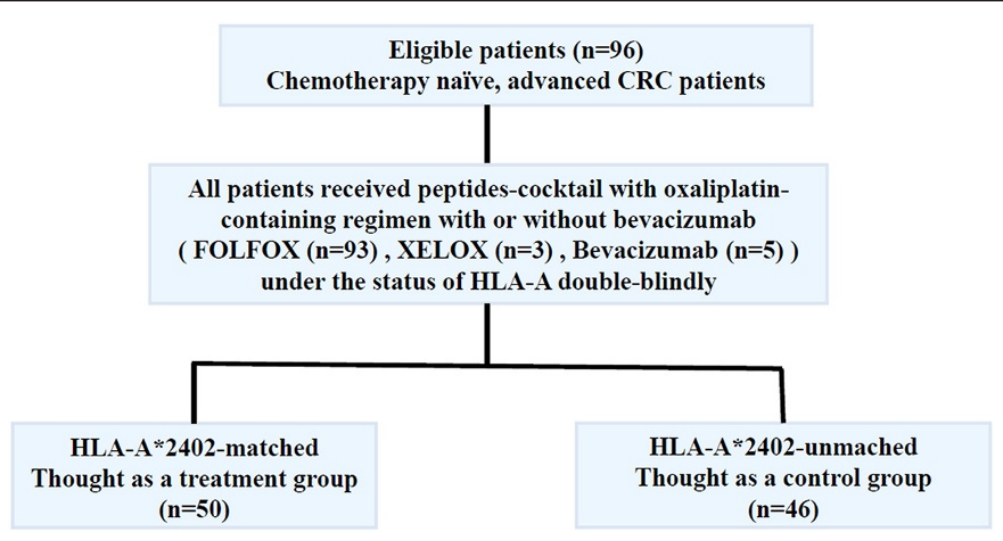

Figure 1 CONSORT diagram. Scheme showing an HLA-A-status double-blind, biologically-randomized phase II study of five therapeutic epitope-peptides combined with oxaliplatin-based chemotherapy as a first-line therapy for advanced colorectal cancer (FXV study). CRC, colorectal cancer; FOLFOX, infusional fluorouracil, leucovorin, and oxaliplatin; XELOX, capecitabine and oxaliplatin; HLA, human leukocyte antigen. 
Table 1 Baseline Patient Characteristics

\begin{tabular}{|c|c|c|c|}
\hline \multirow{2}{*}{ Characteristics } & \multicolumn{2}{|c|}{ HLA-A*2402 } & \multirow[b]{2}{*}{$p$ value } \\
\hline & $\begin{array}{c}\text { Matched } \\
(n=50)\end{array}$ & $\begin{array}{c}\text { Unmatched } \\
(n=46)\end{array}$ & \\
\hline \multicolumn{4}{|l|}{ Sex } \\
\hline Male & 25 & 24 & NS \\
\hline Female & 25 & 22 & \\
\hline \multicolumn{4}{|l|}{ Age } \\
\hline Mean & 64.3 & 63.4 & NS \\
\hline Standard error & 10.9 & 8 & \\
\hline Range & $36-82$ & $38-77$ & \\
\hline \multicolumn{4}{|l|}{ Unresectable site } \\
\hline Liver & 27 & 35 & \\
\hline Lung & 18 & 12 & \\
\hline Dissemination & 5 & 4 & NS \\
\hline Bone & 1 & 2 & \\
\hline Lymphnode & 13 & 13 & \\
\hline Other & 5 & 1 & \\
\hline \multicolumn{4}{|l|}{ Number of unresectable sites } \\
\hline 1 & 36 & 30 & \\
\hline 2 & 9 & 11 & \\
\hline 3 & 5 & 5 & \\
\hline \multicolumn{4}{|l|}{ Resection of primary lesion } \\
\hline yes & 41 & 43 & \\
\hline no & 9 & 3 & NS \\
\hline \multicolumn{4}{|l|}{ Chemotherapy } \\
\hline FOLFOX & 48 & 45 & \\
\hline XELOX & 2 & 1 & NS \\
\hline (Bevacizumab) & 0 & (5) & \\
\hline \multicolumn{4}{|l|}{ Primary minor site } \\
\hline Colon & 29 & 36 & 0.057 \\
\hline Rectal & 21 & 10 & \\
\hline
\end{tabular}

FOLFOX. infusional fluorouracil. leucovorin. and oxaliplatin: XELOX. capecitabine and oxaliplatin; HLA, human leukocyte antigen; NS. not significant.

chemotherapy is more effective for patients with HLAA*2402 positive aCRC when compared to those without HLA-A*2402, defining the HLA-A*2402 matched group as the study group and the unmatched group as the control group. Because the response rate of colorectal cancer patients to first line-treatment is generally about $50 \%$, we estimated that a minimum of 40 patients for both arms would be required, assuming a response rate of $50 \%$ in the
HLA-unmatched control group and 65\% in the HLAmatched study group. A two-sided Alpha level of 0.2 and a beta level of 0.5 were assumed.

Response rates were compared by chi-squared test. OS and PFS rates were analyzed by the Kaplan-Meier method and log rank test. For the evaluation of delayed response, we also performed a supplemental analysis of the weighted log-rank tests with the Harrington-Fleming class of weights test for 3 parameter settings $(\rho=0$ and $\gamma=0.5 ; \rho=0$ and $\gamma=1 ; \rho=0$ and $\gamma=2$ ) [26].

Statistical analyses were performed using SPSS statistics version 20 (SPSS, Chicago, IL, USA) and SAS v9.2. A p value $<0.05$ was considered statistically significant.

\section{Results}

Patients

Between January 2009 and November 2012, ninety-six patients were enrolled in this trial applying the peptide cocktail treatment in combination with an oxaliplatinbased regimen in 13 hospitals. Fifty patients had at least one allele of HLA-A*2402 and forty-six patients had no HLA-A*2402 allele. The peptide vaccination was administered to all patients. Among the 96 patients enrolled to this trial, 93 patients received mFOLFOX6 and three received XELOX. Five patients were additionally treated with bevacizumab (Figure 1). The baseline characteristics were generally well balanced between the HLA-matched and HLA-unmatched groups, although the proportion of rectal cancer was slightly higher in the HLA-matched group (Table 1). On the cut-off date (25 December, 2013), 87 patients (91\%) revealed the progression of the disease with the median OS follow-up period of 38.2 months.

\section{Objective response rate}

The ORR was $62.0 \%$ and $60.9 \%$ in the HLA-matched and HLA-unmatched groups $(\mathrm{p}=0.910)$, respectively (Table 2$)$. The proportions of $\mathrm{CR}, \mathrm{PR}$, and $\mathrm{SD}$ as well as the disease control rate were $2.0 \%$ (1/50), 60.0\% (30/50), 32.0\% (16/50), and $94.0 \%(47 / 50)$ in the HLA-matched group, respectively, and $0 \%$ (0/46), 60.9\% (28/46), 37.0\% (17/46), 97.8\% (45/46) in the HLA-unmatched group, respectively.

\section{Progression free survival}

The median PFS was 7.2 months for the HLA-matched group and 8.7 months for the HLA-unmatched group. There was no significant difference between two groups (Figure 2A, $\mathrm{P}=0.971$ ). We also performed sub-group analyses using

Table 2 Objective Response rate

\begin{tabular}{|c|c|c|c|c|c|c|c|c|}
\hline \multirow{2}{*}{$\begin{array}{l}\text { HLA-status } \\
\text { Response }\end{array}$} & \multicolumn{3}{|c|}{ HLA-A*2402-matched } & \multirow{2}{*}{$\frac{(\mathbf{n}=\mathbf{5 0})}{P D}$} & \multicolumn{3}{|c|}{ HLA-A*2402-unmatched } & \multirow{2}{*}{$\begin{array}{c}(\mathbf{n}=\mathbf{4 6}) \\
P D\end{array}$} \\
\hline & $C R$ & PR & SD & & $C R$ & PR & SD & \\
\hline Number & 1 & 30 & 16 & 3 & 0 & 28 & 17 & 1 \\
\hline Response rate & & $31 / 50$ & $(62.0 \%)$ & & & $28 / 46$ & $(60.9 \%)$ & \\
\hline
\end{tabular}



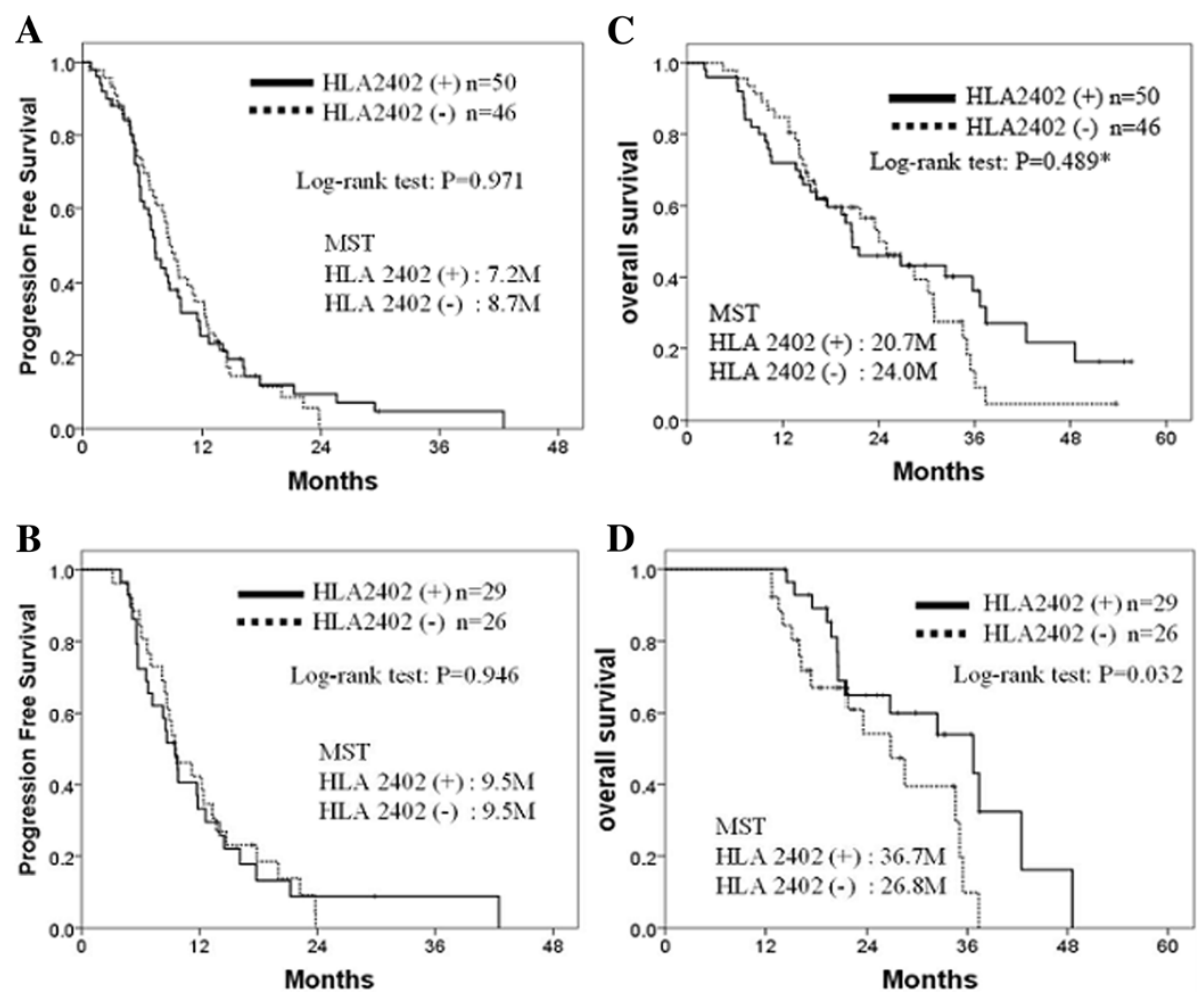

Figure 2 Progression free survival and overall survival. A and $\mathbf{B}$, comparison of progression free survival between HLA-A*2402-mached and -unmatched groups; A, all patients; $\mathbf{B}$, the patients who received the vaccination for more than 12 months. $\mathbf{C}$ and $\mathbf{D}$, comparison of overall survival between HLA-A*2402-matched and -unmatched groups; C, all patients; $\mathbf{D}$, patients who received the vaccination for more than 12 months. MST, median survival time; HLA, human leukocyte antigen; $M$, months; *the weighted log-rank tests with the Harrington-Fleming class of weights were performed and resulted in, $\rho=0$, and $\gamma=0.5, p=0.186 ; \rho=0$, and $\gamma=1, \rho=0.080 ; \rho=0$, and $\gamma=2, \rho=0.101$.

the patients who received the vaccination for more than 12 months, but there was also no difference between these two groups (Figure $2 \mathrm{~B}, \mathrm{P}=0.946$ ).

\section{Overall survival}

The median OS was calculated to be 20.7 months in the HLA-A*2402-matched group and 24.0 months in the unmatched group. There was no significant difference between the two groups (Figure 2C; $\log$-rank test, $\mathrm{p}=$ 0.489; Harrington-Fleming method, $\rho=0$ and $\gamma=0.5$, $\mathrm{p}=0.186 ; \rho=0$ and $\gamma=1, \mathrm{p}=0.080 ; \rho=0$ and $\gamma=2, \mathrm{p}=$ $0.101)$. Interestingly, when the patients were able to receive the vaccination for more than 12 months, the OS of the HLA-A*2402-matched group was significantly better than that of the unmatched group (Figure 2D; log-rank test, $\mathrm{p}=0.032$ ).

\section{Safety}

The most common adverse events (AEs) observed in this trial were neurologic toxicity and hematologic toxicities (Table 3). There was no significant difference in the incidence of AEs including injection site reaction in the two groups. Although the incidences of serious adverse events
(SAEs) were almost similar in the two groups, that of neutropenia was relatively higher in the HLA-A*2402-matched group than the unmatched group. Interstitial pneumonia that led to the death was observed in two cases in the HLA-matched group and in one case in the HLAunmatched group (Table 4).

\section{Immunological biomarkers}

NLR is defined as the neutrophil to lymphocyte ratio, and in this study we categorized the patients into two groups $(<3$ and $\geqq 3)$ according to the papers reported previously [27]. In this study, NLR of $<3.0$ was a prognostic marker for the longer survival with peptide cocktail and oxaliplatin-containing chemotherapy (Figure 3A; log-rank test, $p=0.043)$. The Lymphocyte- $\%$ of $\geqq 15 \%$ was also associated with a long survival (Figure 3B; logrank test, $\mathrm{p}=0.034$ ). Hence, we examined the combined effect of each of these two markers and the HLA types on the clinical efficacy of the vaccination. In patients with a NLR of $<3.0$, a significantly longer overall survival was observed in the HLA-A*2402-matched group than the HLA-A*2402-unmatched group (Figure 3C; log-rank test, $\mathrm{P}=0.289$; Harrington-Fleming method, $\rho=0$ and $\gamma=$ 
Table 3 Frequent and Severe Adverse Events (CTCAE version 3.0)

\begin{tabular}{|c|c|c|c|c|c|c|c|c|c|c|c|c|c|c|c|c|c|c|c|c|}
\hline \multicolumn{21}{|c|}{ FOLFOX $(n=89)$, FOLFOX $+\operatorname{Bev}(n=4), \operatorname{XELOX}+\operatorname{Bev}(n=1)$} \\
\hline & \multicolumn{10}{|c|}{ HLA-A*2402-matched $(n=50)$} & \multicolumn{10}{|c|}{ HLA-A*2402-unmatched $(n=46)$} \\
\hline & \multicolumn{10}{|c|}{ FOLFOX $(n=48)$, XELOX $(n=2)$} & \multicolumn{10}{|c|}{ FOLFOX $(n=41)+\operatorname{Bev}(n=4), \operatorname{XELOX}+\operatorname{Bev}(n=1)$} \\
\hline \multirow{2}{*}{ Adverse Event } & \multicolumn{2}{|c|}{1} & \multicolumn{2}{|c|}{2} & \multicolumn{2}{|c|}{3} & \multicolumn{2}{|c|}{4} & \multicolumn{2}{|c|}{5} & \multicolumn{2}{|c|}{1} & \multicolumn{2}{|c|}{2} & \multicolumn{2}{|c|}{3} & \multicolumn{2}{|c|}{4} & \multicolumn{2}{|c|}{5} \\
\hline & No & $\%$ & No & $\%$ & No & $\%$ & No & $\%$ & No & $\%$ & No & $\%$ & No & $\%$ & No & $\%$ & No & $\%$ & No & $\%$ \\
\hline Hand-foot syndrome & 0 & 0 & 0 & 0 & 1 & 2 & 0 & 0 & 0 & 0 & 1 & 2 & 0 & 0 & 1 & 2 & 0 & 0 & 0 & 0 \\
\hline Allergy & 4 & 8 & 3 & 6 & 2 & 4 & 0 & 0 & 0 & 0 & 3 & 7 & 4 & 9 & 0 & 0 & 0 & 0 & 0 & 0 \\
\hline Mucositis & 2 & 4 & 1 & 2 & 1 & 2 & 0 & 0 & 0 & 0 & 2 & 4 & 0 & 0 & 0 & 0 & 0 & 0 & 0 & 0 \\
\hline Nausea/vomiting & 5 & 10 & 1 & 2 & 2 & 4 & 0 & 0 & 0 & 0 & 6 & 13 & 2 & 4 & 1 & 2 & 0 & 0 & 0 & 0 \\
\hline Neurologic toxicity & 15 & 30 & 10 & 20 & 4 & 8 & 0 & & 0 & 0 & 17 & 37 & 10 & 22 & 5 & 11 & 1 & 2 & 0 & 0 \\
\hline Anorexia & 10 & 20 & 3 & 6 & 4 & 8 & 0 & 0 & 0 & 0 & 10 & 22 & 4 & 9 & 2 & 4 & 0 & 0 & 0 & 0 \\
\hline Diarrhea & 3 & 6 & 6 & 12 & 2 & 4 & 0 & 0 & 0 & 0 & 3 & 7 & 0 & 0 & 1 & 2 & 0 & 0 & 0 & 0 \\
\hline Fatigue/Asthenia & 5 & 10 & 1 & 2 & 2 & 4 & 0 & 0 & 0 & 0 & 5 & 11 & 1 & 2 & 1 & 2 & 0 & 0 & 0 & 0 \\
\hline Fever & 2 & 4 & 0 & 0 & 0 & 0 & 0 & 0 & 0 & 0 & 3 & 7 & 2 & 4 & 0 & 0 & 0 & 0 & 0 & 0 \\
\hline Injection site reaction & 18 & 36 & 18 & 36 & 9 & 18 & 0 & 0 & 0 & 0 & 20 & 43 & 17 & 37 & 3 & 13 & 0 & 0 & 0 & 0 \\
\hline Interstitial pneumonia & 0 & 0 & 0 & 0 & 4 & 8 & 0 & 0 & 2 & 4 & 0 & 0 & 0 & 0 & 4 & 9 & 0 & 0 & 1 & 2 \\
\hline Neutropenia & 5 & 10 & 10 & 20 & 10 & 20 & 1 & 2 & 0 & 0 & 8 & 17 & 14 & 30 & 2 & 4 & 1 & 2 & 0 & 0 \\
\hline Leukopenia & 10 & 20 & 12 & 24 & 1 & 2 & 0 & 0 & 0 & 0 & 12 & 26 & 9 & 20 & 2 & 4 & 0 & 0 & 0 & 0 \\
\hline Thrombocytopenia & 17 & 34 & 3 & 6 & 0 & 0 & 0 & 0 & 0 & 0 & 20 & 43 & 2 & 4 & 0 & 0 & 0 & 0 & 0 & 0 \\
\hline Bilirubin & 2 & 4 & 2 & 4 & 0 & 0 & 0 & 0 & 0 & 0 & 0 & 0 & 0 & 0 & 0 & 0 & 0 & 0 & 0 & 0 \\
\hline$A L-P$ & 11 & 22 & 1 & 2 & 1 & 2 & 0 & 0 & 0 & 0 & 10 & 22 & 1 & 2 & 0 & 0 & 0 & 0 & 0 & 0 \\
\hline Creatinine & 3 & 6 & 1 & 2 & 0 & 0 & 0 & 0 & 0 & 0 & 1 & 2 & 0 & 0 & 0 & 0 & 0 & 0 & 0 & 0 \\
\hline Hemoglobin & 11 & 22 & 5 & 10 & 0 & 0 & 0 & 0 & 0 & 0 & 13 & 28 & 7 & 15 & 0 & 0 & 0 & 0 & 0 & 0 \\
\hline Embolism & 0 & 0 & 0 & 0 & 0 & 0 & 0 & 0 & 0 & 0 & 0 & 0 & 0 & 0 & 0 & 0 & 1 & 2 & 0 & 0 \\
\hline AST/ALT & 12 & 24 & 0 & 0 & 1 & 2 & 0 & 0 & 0 & 0 & 6 & 13 & 1 & 2 & 0 & 0 & 0 & 0 & 0 & 0 \\
\hline
\end{tabular}

No gastrointestinal perforation nor bleeding wound healing complication was observed. FOLFOX, infusional fluorouracil, leucovorin, and oxaliplatin; XELOX, capecitabine and oxaliplatin; Bev, bevacizumab; AL-P, alkaline phosphatese; AST, aspartete aminotransfarase; ALT, alanine aminotransferase; CTCAE, the Common Terminology Criteria for Adverse Event version 3.0; HLA, Human leukocyte antigen.

$0.5, \mathrm{p}=0.152 ; \rho=0$ and $\gamma=1, \mathrm{p}=0.064 ; \rho=0$ and $\gamma=2$, $\mathrm{p}=0.035)$ while this difference was not observed in patients with NLR of $\geqq 3.0$ (log-lank test, $\mathrm{p}=0.962$; Harrington-Fleming method, $\rho=0$ and $\gamma=0.5, p=0.495$; $\rho=0$ and $\gamma=1, p=0.346 ; \rho=0$ and $\gamma=2, p=0.251)$. Similarly, in a patient group with a lymphocyte\% of $>15 \%$, a longer overall survival was observed in the HLA-A*2402matched group (Figure 3D; log-lank test, $\mathrm{p}=0.340$; Harrington-Fleming method, $\rho=0$ and $\gamma=0.5, p=0.114$; $\rho=0$ and $\gamma=1, p=0.051 ; \rho=0$ and $\gamma=2, p=0.029)$.

\section{Discussion}

We performed a phase II study using a cocktail of five epitope peptides, which we previously confirmed its safety, together with oxaliplatin-based chemotherapy. The cocktail contained three peptides derived from three oncoantigens and two peptides targeting VEGFR1 and VEGFR2. This study was an HLA-A-status double-blind, phase II study of five therapeutic epitope-peptides with oxaliplatinbased chemotherapy as a first-line therapy for advanced
Table 4 Interstitial Pneumonia

\begin{tabular}{lcc}
\hline $\begin{array}{c}\text { HLA } \\
\text { genotype }\end{array}$ & $\begin{array}{c}\text { CTCAE } \\
\text { grade }\end{array}$ & $\begin{array}{c}\text { Result of } \\
\text { DLLT }\end{array}$ \\
\hline $2402 / 2402$ & 3 & $5 \mathrm{FU}$ \\
$2402 / 1101$ & 3 & negative \\
$2402 / 1101$ & 5 & negative \\
$2402 / 0206$ & 3 & negative \\
$2402 / 2603$ & 3 & $5 \mathrm{FU}$ \\
$2402 / 2602$ & 5 & negative \\
$1101 / 2601$ & 3 & $5 \mathrm{FU}$ \\
$2601 / 3101$ & 3 & $5 \mathrm{FU}$ \\
$1101 / 3101$ & 3 & $5 \mathrm{FU}$ \\
$3004 / 3303$ & 5 & not examined \\
$1101 / 3101$ & 3 & not examined \\
\hline
\end{tabular}

CTCAE, the Common Terminology Criteria for Adverse Event version 3.0; HLA, Human leukocyte antigen; DLTT, drug-induced lymphocyte transformation test; 5FU, 5-fluorouracil. 

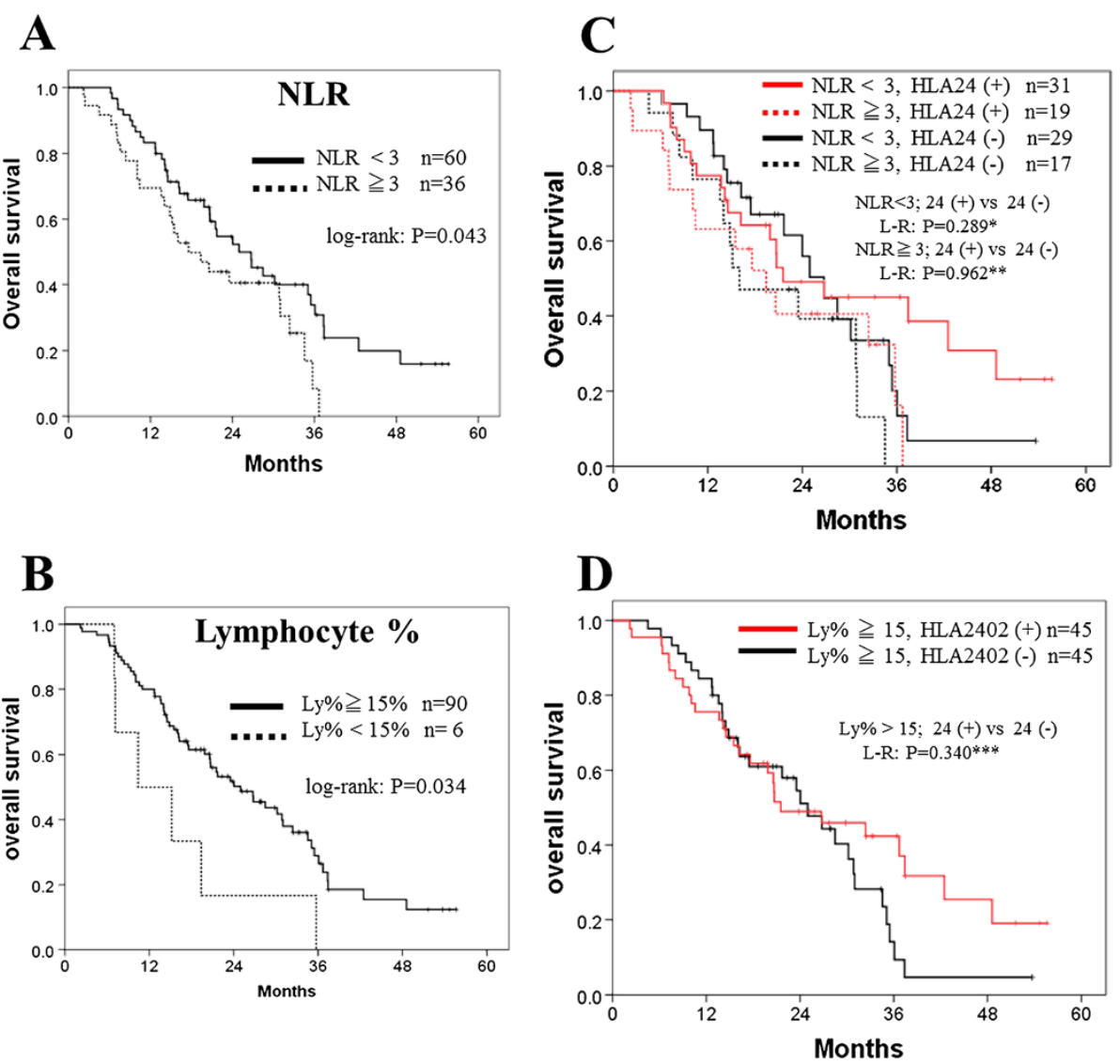

Figure 3 Biomarkers for the survival and the clinical efficacy of vaccination. Neutrophil/lymphocyte ratio (NLR) $<3.0$ and Lymphocyte-\% $\geqq$ $15 \%$ were considered as indicative factors. $\mathbf{A}$ and $\mathbf{B}$, comparison between the favorite group and others. $\mathbf{C}$, comparison of the patients with a NLR of $\geqq 3$ or a NLR of $<3$ between the HLA-A*2402-matched and -unmatched groups. D, comparison of the patients with Lymphocyte- $\% \geqq 15 \%$ between the HLA-A*2402 positive and negative groups. Lymphocyte (Ly)-\%, the percentage of lymphocytes among the peripheral leukocytes; $\mathrm{NLR}$, neutrophil/lymphocyte ratio; HLA, human leukocyte antigen; L-R, log-rank test; *the weighted log-rank tests with the Harrington-Fleming class of weights were performed and resulted in, $\rho=0$, and $\gamma=0.5, p=0.152 ; \rho=0$, and $\gamma=1, p=0.064 ; \rho=0$, and $\gamma=2, p=0.035$; **the Harrington-Fleming tests were resulted in, $\rho=0$, and $\gamma=0.5, p=0.495 ; \rho=0$, and $\gamma=1, \rho=0.346 ; \rho=0$, and $\gamma=2, \rho=0.251$; *** the Harrington-Fleming tests were resulted in, $\rho=0$, and $\gamma=0.5, p=0.114 ; \rho=0$, and $\gamma=1, \rho=0.051 ; \rho=0$, and $\gamma=2, \rho=0.029$.

colorectal cancer (FXV study). In this study, we observed many interesting results.

Firstly, the OS of the HLA-A*2402-matched group was significantly higher compared to that of the unmatched group (log-rank test, $\mathrm{p}=0.032$ ) when patients who received the vaccination for more than 12 months (Figure 2D) although no difference in PFS was observed between the two groups (Figures 2B). These results indicated that the additional effect of vaccination on the standard chemotherapy was likely to be slow-acting as this kind of delayed response by the vaccine treatment was indicated in the guidance for therapeutic cancer vaccines released from the US Food and Drug Administration in October, 2011 [28].

Secondly, neutrophil/lymphocyte ratio (NLR) might become a prognostic marker for patients who received the peptide vaccine in combination with standard chemotherapy (Figure 3A, log-rank; $\mathrm{p}=0.043$ ), and there was an obvious tail effect for extremely long survival. Then we examined the efficacy of vaccination by comparing HLAmatched group and -unmatched group. In patients with an NLR of $<3.0$, a significantly longer survival in the HLA-matched group than the HLA-unmatched group was observed (Figure 3B; log-rank, $\mathrm{p}=0.289$; HarringtonFleming, $\mathrm{p}=0.035$ ), while this difference was not observed in the two groups with NLR of $\geqq 3.0$ (log-rank, $p=0.962$; Harrington-Fleming, $\mathrm{p}=0.251$ ). This result also support the idea that it may be critically important to apply vaccine treatment to patients with better immune status, and NLR might be a one of good predictive markers to select the appropriate patient populations for this type of treatment. A similar result was observed when we analyzed patients with lymphocyte\% of $\geqq 15 \%$; HLA-matched patients with lymphocyte\% of $\geqq 15$ showed significantly better prognosis than HLA-unmatched patients (Figure 3D; log-rank, $\mathrm{p}=0.340$; Harrington-Fleming, 
$p=0.029$ ). The selection of patients with lower NLR and higher lymphocyte percentage might be useful to the selection of patients who are likely to respond well to vaccine treatment and improve clinical outcomes.

Vaccinations with a cocktail of five peptides together with oxaliplatin-based chemotherapy in metastatic CRC patients were well tolerated, except for relatively frequent cases (11 cases; 11.4\%) of pneumonitis (Tables 3 and 4), whose incidence seemed to be higher than previously reported for oxaliplatin-based chemotherapies although no difference was observed between HLA-matched and -unmatched group. Correale et al. reported two cases (5.5\%) in 36 patients with advanced gastric cancer treated with gemcitabine plus oxaliplatin, folinic acid, and 5-fluorouracil (FOLFOX-4) [29]. Usui et al. reported that four cases (3.9\%) of pneumonitis among 104 Japanese patients treated with oxaliplatin-containing regimes for advanced colorectal cancer [30]. In addition, there have been many case reports of oxaliplatin-related pneumonitis [31-35]. In this study, eleven (11.4\%) of 96 patients suffered from severe pneumonitis including three cases with grade 5 pneumonitis. To investigate the possible cause of pneumonitiswe performed drug-induced lymphocyte transformation test (DLTT) for nine patients whose samples were available. Among them, five patients (55.6\%) were judged to be positive to fluorouracil alone, and the remaining four patients were negative for all of the antigens tested. Although the size of this study is not large enough to make any conclusion and there is no difference between the two groups, this adverse event should be carefully monitored when we will perform the next-step clinical trial.

Although the efficacy of our peptide vaccine was not clearly demonstrated in this phase II study, the timing of and combination treatment with vaccination might not be optimized, and the sample size was limited. Recently, regulatory $\mathrm{T}$ cells (Tregs) and myeloid-derived suppressor cells (MDSCs) are reported as potent immunosuppressive cells to protect cancer cells from the host immune system [36,37]. Over expression of PD-L1and PD-1 as well as up-regulation of indoleamine-2,3-dioxygenase (IDO) in the tumor microenvironment also inhibit the CTL functions [38]. Hence, to overcome these immune-escape mechanisms, various approaches have been taken in the last decade [39,40]. For example, anti-PD1antibody [41], anti-PD-L1antibody [42], and anti-CTL4 antibody [43] were applied in clinical trials to overcome the suppressive immuno checkpoints, and surprisingly high objective response rates were observed in many types of malignant neoplasm. Small-molecule inhibitors [44] that block IDO enzymatic activity or cyclophosphamide to reduce the number of Tregs [45] were also applied in clinical trials to dissolve the suppressive immunity. For the successful next generation immunotherapy, peptide vaccine should be combined with some agents to modify the immunesuppressive tumor microenvironments.

In conclusion, our cocktail of five therapeutic epitope peptides appears to be effective in a subset of patients, and warrants a randomized phase III study. In the phase III study, biomarkers such as NLR and lymphocyte-\% might be useful for assessing the response to the peptide vaccine and for selecting patients likely to have a better treatment outcome with the vaccination.

\section{Conclusions}

This phase II cancer vaccine therapy demonstrated that our therapeutic peptides cocktail was likely to be effective in a subset of patients and warrants a randomized phase III study. In the phase III study, predictive biomarkers such as NLR and lymphocyte-\% should be used for its response and for selecting patients to have a better treatment outcome with the vaccination.

\section{Additional file}

\section{Additional file 1: Summary of the protocol.}

\section{Abbreviations}

RNF43: Ring finger protein 43; TOMM34: 34 kDa-translocase of the outer mitochondrial membrane; KOC1: insulin-like growth factor-II mRNA binding protein 3; VEGFR: Vascular endothelial growth factor receptor; HPLC: High performance liquid chromatography; CRC: Colorectal cancer;

ELISPOT: Enzyme-linked immunospot; PBMC: Peripheral blood mononuclear cells; CTL: Cytotoxic T lymphocytes; RR: Response rates; CR: Complete clinical response; SD: Stable disease; PD: Progressive disease; PFS: Progression free survival; OS: Overall survival; HLA: Human leukocyte antigen; MST: Median overall survival time; ECOG: Eastern cooperative oncology group;

RECIST: Response evaluation criteria in solid tumors; TIL: Tumor infiltrating cells; CTCAE: Common terminology criteria for adverse events version3.0; AEs: Adverse events; SAEs: Serious adverse events; DLTT: Drug-induced lymphocyte transformation test; PS: Performance status; IFA: Incomplete freund's adjuvant; CT: Computed tomography; MRI: Magnetic resonance imaging; NLR: Neutrophil/lymphocyte ratio; FOLFOX: Infusional fluorouracil, leucovorin, and oxaliplatin; XELOX: Capecitabine and oxaliplatin, Tregs, regulatory T cells; MDSCs: Myeloid-derived suppressor cells; IDO: Indoleamine-2,3dioxygenase.

\section{Competing interests}

Yusuke Nakamura is a stock holder and a scientific advisor of OncoTherapy Science, Inc. The other authors have no potential conflicts of interest to disclose.

\section{Authors' contributions}

SH designed, performed and evaluated clinical study, and wrote the manuscript. YN and $\mathrm{MO}$ participated in the design, review and revision of the manuscript. HT, KH, KT, RS, HO, RE, FS, KO, TF, TN, KS, KY, YI, SK, YS, NS, SY, HS, AK, TF, YK and HF assisted to perform clinical study. RT, HT, and TY contributed in the data collection and statistical analysis. All authors participated in the data acquisition and discussion of the manuscript and approved the final manuscript.

\section{Acknowledgements}

This study was supported partially by the Project for Development of Innovative Research on Cancer Therapeutics (P-DIRECT) of the Ministry of Education, Culture, Sports, Science and Technology of Japan. The authors would like to thank Prof. Yusuke Nakamura, Dr. Takuya Tsunoda, Dr. Koji Yoshida, Laboratory of Molecular Medicine, Human Genome Center, Institute of Medical Science, The University of Tokyo, for their excellent advice and 
cooperation and providing all the peptides. The authors also thank Prof. Koj Kono, Department of Surgery, National University of Singapore, for his excellent managements as The Data and Safety Monitoring Committee of this study.

\section{Author details}

${ }^{1}$ Department of Digestive Surgery and Surgical Oncology, Yamaguchi University Graduate School of Medicine, Ube, Japan. ${ }^{2}$ Department of Medicine and Surgery, The University of Chicago, Chicago, IL, USA. ${ }^{3}$ Department of Surgical Oncology, Osaka City University Graduate School of Medicine, Osaka, Japan. ${ }^{4}$ Department of Surgery, Kure-Kyosai Hospital, Kure, Japan. ${ }^{5}$ Department of Surgery, Ogori Daiichi General Hospital, Yamaguchi, Japan. ${ }^{6}$ Department of Surgery, Kinki University Faculty of Medicine, Osaka-Sayama, Japan. 'Department of Surgery, Kanmon-Medical Center, Shimonoseki, Japan. ${ }^{8}$ Department of Surgery, Shimonoseki-Kosei Hospital, Shimonoseki, Japan. 'Tokyo Women's Medical University Medical Center East, Tokyo, Japan. ${ }^{10}$ Department of Pharmacy, Yamaguchi University Hospital, Ube, Japan. ${ }^{11}$ Department of Biostatistics, National Cancer Center, Chiba, Japan. ${ }^{12}$ Division of Cellular Signaling, Institute for Advanced Medical Research, Keio University School of Medicine, Tokyo, Japan.

Received: 10 March 2014 Accepted: 16 April 2014

Published: 30 April 2014

\section{References}

1. Ferlay J, Shin HR, Bray F, Forman D, Mathers C, Parkin DM: Estimates of worldwide burden of cancer in 2008: GLOBOCAN 2008. Int J Cancer 2010, 127:2893-2917.

2. Tournigand C, Andre T, Achille E, Lledo G, Flesh M, Mery-Mignard D, Quinaux E, Couteau C, Buyse M, Ganem G, Landi B, Colin P, Louvet C, de Gramont A: FOLFIRI followed by FOLFOX6 or the reverse sequence in advanced colorectal cancer: a randomized GERCOR study. J Clin Oncol 2004, 22:229-237.

3. Cassidy J, Clarke S, Diaz-Rubio E, Scheithauer W, Figer A, Wong R, Koski S, Lichinitser M, Yang TS, Rivera F, Couture F, Sirzen F, Saltz L: Randomized phase III study of capecitabine plus oxaliplatin compared with fluorouracil/ folinic acid plus oxaliplatin as first-line therapy for metastatic colorectal cancer. J Clin Oncol 2008, 26:2006-2012.

4. Saltz LB, Clarke S, Diaz-Rubio E, Scheithauer W, Figer A, Wong R, Koski S, Lichinitser M, Yang TS, Rivera F, Couture F, Sirzen F, Cassidy J: Bevacizumab in combination with oxaliplatin-based chemotherapy as first-line therapy in metastatic colorectal cancer: a randomized phase III study. J Clin Oncol 2008, 26:2013-2019.

5. Van Cutsem E, Kohne CH, Hitre E, Zaluski J, Chang Chien CR, Makhson A, D'Haens G, Pinter T, Lim R, Bodoky G, Roh JK, Folprecht G, Ruff P, Stroh C, Tejpar S, Schlichting M, Nippgen J, Rougier P: Cetuximab and chemotherapy as initial treatment for metastatic colorectal cancer. N Engl J Med 2009, 360:1408-1417.

6. Douillard JY, Siena S, Cassidy J, Tabernero J, Burkes R, Barugel M, Humblet Y, Bodoky G, Cunningham D, Jassem J, Rivera F, Kocakova I, Ruff P, Blasinska-Morawiec M, Smakal M, Canon JL, Rother M, Oliner KS, Wolf M, Gansert J: Randomized, phase III trial of panitumumab with infusional fluorouracil, leucovorin, and oxaliplatin (FOLFOX4) versus FOLFOX4 alone as first-line treatment in patients with previously untreated metastatic colorectal cancer: the PRIME study. J Clin Oncol 2010, 28:4697-4705

7. Okabe H, Satoh S, Kato T, Kitahara O, Yanagawa R, Yamaoka Y, Tsunoda T, Furukawa $Y$, Nakamura Y: Genome-wide analysis of gene expression in human hepatocellular carcinomas using CDNA microarray: identification of genes involved in viral carcinogenesis and tumor progression. Cancer Res 2001, 61:2129-2137.

8. Yagyu R, Furukawa Y, Lin YM, Shimokawa T, Yamamura T, Nakamura Y: A novel oncoprotein RNF43 functions in an autocrine manner in colorectal cancer. Int J Oncol 2004, 25:1343-1348.

9. Shimokawa T, Matsushima S, Tsunoda T, Tahara H, Nakamura Y, Furukawa Y: Identification of TOMM34, which shows elevated expression in the majority of human colon cancers, as a novel drug target. Int J Oncol 2006, 29:381-386.

10. Kikuchi T, Daigo Y, Katagiri T, Tsunoda T, Okada K, Kakiuchi S, Zembutsu H, Furukawa Y, Kawamura M, Kobayashi K, Imai K, Nakamura Y: Expression profiles of non-small cell lung cancers on CDNA microarrays: identification of genes for prediction of lymph-node metastasis and sensitivity to anti-cancer drugs. Oncogene 2003, 22:2192-2205.

11. Rosenberg SA, Yang JC, Restifo NP: Cancer immunotherapy: moving beyond current vaccines. Nat Med 2004, 10:909-915.

12. Khong HT, Restifo NP: Natural selection of tumor variants in the generation of tumor "escape" phenotypes. Nat Immunol 2002, 3:999-1005.

13. Ryschich E, Notzel T, Hinz U, Autschbach F, Ferguson J, Simon I, Weitz J, Frohlich B, Klar E, Buchler MW, Schmidt J: Control of T-cell-mediated immune response by HLA class I in human pancreatic carcinoma. Clin Cancer Res 2005, 11:498-504.

14. Folkman J: Tumor angiogenesis: therapeutic implications. N Engl J Med 1971, 285:1182-1186.

15. Olofsson B, Korpelainen E, Pepper MS, Mandriota SJ, Aase K, Kumar V, Gunji Y, Jeltsch MM, Shibuya M, Alitalo K, Eriksson U: Vascular endothelial growth factor $B$ (VEGF-B) binds to VEGF receptor-1 and regulates plasminogen activator activity in endothelial cells. Proc Natl Acad Sci U S A 1998, 95:11709-11714.

16. Millauer B, Wizigmann-Voos S, Schnurch H, Martinez R, Moller NP, Risau W, Ullrich A: High affinity VEGF binding and developmental expression suggest Flk-1 as a major regulator of vasculogenesis and angiogenesis. Cell 1993, 72:835-846.

17. Date Y, Kimura A, Kato H, Sasazuki T: DNA typing of the HLA-A gene: population study and identification of four new alleles in Japanese. Tissue Antigens 1996, 47:93-101.

18. Hazama S, Nakamura Y, Takenouchi H, Suzuki N, Tsunedomi R, Inoue $Y$, Tokuhisa Y, lizuka N, Yoshino S, Takeda K, Shinozaki H, Kamiya A, Furukawa $\mathrm{H}, \mathrm{Oka} \mathrm{M}$ : A phase I study of combination vaccine treatment of five therapeutic epitope-peptides for metastatic colorectal cancer; safety, immunological response, and clinical outcome. J Trans/ Med 2014, 12:63.

19. Maeda K, Hazama S, Tokuno K, Kan S, Maeda Y, Watanabe Y, Kamei R, Shindo Y, Maeda N, Yoshimura K, Yoshino S, Oka M: Impact of chemotherapy for colorectal cancer on regulatory T-cells and tumor immunity. Anticancer Res 2011, 31:4569-4574.

20. Uchida N, Tsunoda T, Wada S, Furukawa Y, Nakamura Y, Tahara H: Ring finger protein 43 as a new target for cancer immunotherapy. Clin Cancer Res 2004, 10:8577-8586.

21. Suda T, Tsunoda T, Daigo Y, Nakamura Y, Tahara H: Identification of human leukocyte antigen-A24-restricted epitope peptides derived from gene products upregulated in lung and esophageal cancers as novel targets for immunotherapy. Cancer Sci 2007, 98:1803-1808.

22. Ishizaki H, Tsunoda T, Wada S, Yamauchi M, Shibuya M, Tahara H: Inhibition of tumor growth with antiangiogenic cancer vaccine using epitope peptides derived from human vascular endothelial growth factor receptor 1. Clin Cancer Res 2006, 12:5841-5849.

23. Wada S, Tsunoda T, Baba T, Primus FJ, Kuwano H, Shibuya M, Tahara H: Rationale for antiangiogenic cancer therapy with vaccination using epitope peptides derived from human vascular endothelial growth factor receptor 2. Cancer Res 2005, 65:4939-4946.

24. Kato T, Muro K, Yamaguchi K, Bando H, Hazama S, Amagai K, Baba H, Denda T, Shi $X$, Fukase K, Skamoto J, Mishima H: Cediranib in combination with mFOLFOX6 in Japanese patients with metastatic colorectal cancer: results from the randomised phase II part of a phase 1/II study. Ann Oncol 2012, 23:933-941.

25. Schmoll HJ, Cunningham D, Sobrero A, Karapetis CS, Rougier P, Koski SL, Kocakova I, Bondarenko I, Bodoky G, Mainwaring P, Salazar R, Barker P, Mookerjee B, Robertson J, Van Cutsem E: Cediranib with mFOLFOX6 versus bevacizumab with mFOLFOX6 as first-line treatment for patients with advanced colorectal cancer: a double-blind, randomized phase III study (HORIZON III). J Clin Oncol 2012, 30:3588-3595.

26. Fleming T, Harrington D: Counting Processes and Survival Analysis. New York: John Wiley \& Sons; 1991.

27. He W, Yin C, Guo G, Jiang C, Wang F, Qiu H, Chen X, Rong R, Zhang B, Xia L: Initial neutrophil lymphocyte ratio is superior to platelet lymphocyte ratio as an adverse prognostic and predictive factor in metastatic colorectal cancer. Med Oncol 2013, 30:439.

28. U.S. Department of Health and Human Services, Food and Drug Administration: Guidance for Industry. Clinical Considerations for Therapeutic Cancer Vaccines. 2011, http://www.fda.gov/downloads/ biologicsbloodvaccines/guidancecomplianceregulatoryinformation/ guidances/vaccines/ucm278673.pdf.

29. Correale P, Fulfaro F, Marsili S, Cicero G, Bajardi E, Intrivici C, Vuolo G, Carli AF, Caraglia M, Del Prete S, Greco E, Gebbia N, Francini G: Gemcitabine (GEM) plus oxaliplatin, folinic acid, and 5-fluorouracil (FOLFOX-4) in 
patients with advanced gastric cancer. Cancer Chemother Pharmacol 2005, 56:563-568

30. Usui K, Katou Y, Furushima K, Tanaka Y, Tanai C, Ishihara T: Interstitial lung disease during chemotherapy combined with oxaliplatin and/or bevacizumab in advanced colorectal cancer patients. Jpn J Clin Oncol 2011, 41:498-502.

31. Gagnadoux F, Roiron C, Carrie E, Monnier-Cholley L, Lebeau B: Eosinophilic lung disease under chemotherapy with oxaliplatin for colorectal cancer. Am J Clin Oncol 2002, 25:388-390.

32. Fuse N, Doi T, Ohtsu A, Takeuchi S, Kojima T, Taku K, Tahara M, Muto M, Asaka M, Yoshida S: Feasibility of oxaliplatin and infusional fluorouracil/ leucovorin (FOLFOX4) for Japanese patients with unresectable metastatic colorectal cancer. Jpn J Clin Oncol 2007, 37:434-439.

33. Arevalo Lobera S, Sagastibeltza Marinelarena N, Elejoste Echeberria I, Mele Olive M, Egana Otano L, Basterretxea Badiola L, La Casta Munoa A, Azkue Gabilondo M: Fatal pneumonitis induced by oxaliplatin. Clin Transl Oncol 2008, 10:764-767.

34. Pontes LB, Armentano DP, Soares A, Gansl RC: Fatal pneumonitis induced by oxaliplatin: description of three cases. Case Rep Oncol 2012, 5:104-109.

35. Muneoka K, Shirai Y, Sasaki M, Wakai T, Sakata J, Hatakeyama K: Interstitial pneumonia arising in a patient treated with oxaliplatin, 5-fluorouracil, and, leucovorin (FOLFOX). Int J Clin Oncol 2009, 14:457-459.

36. Facciabene A, Motz GT, Coukos G: T-regulatory cells: key players in tumor immune escape and angiogenesis. Cancer Res 2012, 72:2162-2171.

37. Lindau D, Gielen P, Kroesen M, Wesseling P, Adema GJ: The immunosuppressive tumour network: myeloid-derived suppressor cells, regulatory T cells and natural killer T cells. Immunology 2013, 138:105-115.

38. Gajewski TF, Schreiber H, Fu YX: Innate and adaptive immune cells in the tumor microenvironment. Nat Immunol 2013, 14:1014-1022.

39. Okazaki T, Tanaka Y, Nishio R, Mitsuiye T, Mizoguchi A, Wang J, Ishida M, Hiai H, Matsumori A, Minato N, Honjo T: Autoantibodies against cardiac troponin I are responsible for dilated cardiomyopathy in PD-1-deficient mice. Nat Med 2003, 9:1477-1483.

40. Pardoll DM: The blockade of immune checkpoints in cancer immunotherapy. Nat Rev Cancer 2012, 12:252-264.

41. Topalian SL, Hodi FS, Brahmer JR, Gettinger SN, Smith DC, McDermott DF, Powderly JD, Carvajal RD, Sosman JA, Atkins MB, Leming PD, Spigel DR, Antonia SJ, Horn L, Drake CG, Pardoll DM, Chen L, Sharfman WH, Anders RA, Taube JM, McMiller TL, Xu H, Korman AJ, Jure-Kunkel M, Agrawal S, McDonald D, Kollia GD, Gupta A, Wigginton JM, Sznol M: Safety, activity, and immune correlates of anti-PD-1 antibody in cancer. N Engl J Med 2012, 366:2443-2454.

42. Brahmer JR, Tykodi SS, Chow LQ, Hwu WJ, Topalian SL, Hwu P, Drake CG, Camacho LH, Kauh J, Odunsi K, Pitot HC, Hamid O, Bhatia S, Martins R, Eaton K, Chen S, Salay TM, Alaparthy S, Grosso JF, Korman AJ, Parker SM, Agrawal S, Goldberg SM, Pardoll DM, Gupta A, Wigginton JM: Safety and activity of anti-PD-L1 antibody in patients with advanced cancer. N Engl $J$ Med 2012, 366:2455-2465.

43. Wolchok JD, Kluger H, Callahan MK, Postow MA, Rizvi NA, Lesokhin AM, Segal NH, Ariyan CE, Gordon RA, Reed K, Burke MM, Caldwell A, Kronenberg SA, Agunwamba BU, Zhang X, Lowy I, Inzunza HD, Feely W, Horak CE, Hong Q, Korman AJ, Wigginton JM, Gupta A, Sznol M: Nivolumab plus ipilimumab in advanced melanoma. N Engl J Med 2013, 369:122-133.

44. Liu X, Shin N, Koblish HK, Yang G, Wang Q, Wang K, Leffet L, Hansbury MJ, Thomas B, Rupar M, Waeltz P, Bowman KJ, Polam P, Sparks RB, Yue EW, Li Y, Wynn R, Fridman JS, Burn TC, Combs AP, Newton RC, Scherle PA: Selective inhibition of IDO1 effectively regulates mediators of antitumor immunity. Blood 2010, 115:3520-3530.

45. Walter S, Weinschenk T, Stenzl A, Zdrojowy R, Pluzanska A, Szczylik C, Staehler M, Brugger W, Dietrich PY, Mendrzyk R, Hilf N, Schoor O, Fritsche J, Mahr A, Maurer D, Vass V, Trautwein C, Lewandrowski P, Flohr C, Pohla H, Stanczak JJ, Bronte V, Mandruzzato S, Biedermann T, Pawelec G, Derhovanessian E, Yamagishi H, Miki T, Hongo F, Takaha N: Multipeptide immune response to cancer vaccine IMA901 after single-dose cyclophosphamide associates with longer patient survival. Nat Med 2012, 18:1254-1261.

\section{doi:10.1186/1479-5876-12-108}

Cite this article as: Hazama et al.: A phase II study of five peptides combination with oxaliplatin-based chemotherapy as a first-line therapy for advanced colorectal cancer (FXV study). Journal of Translational Medicine 2014 12:108.

\section{Submit your next manuscript to BioMed Central and take full advantage of:}

- Convenient online submission

- Thorough peer review

- No space constraints or color figure charges

- Immediate publication on acceptance

- Inclusion in PubMed, CAS, Scopus and Google Scholar

- Research which is freely available for redistribution 